\title{
دوافع التكتلات الاقتصادية في الدول الإفريقية
}

خالد غازي سالم الهاجري

طالب بمعهد البحوث والدراسات الإفريقية ودول حوض النيل

جامعة أسوان

رجب عحمد حنفي

أستاذ الاقتصاد الزراعي، كلية الزراعة البيئية، جامعه العريش.

حرب أحمد البرديسى

أستاذ مساعد ورئيس قسم الاقتصاد الزراعي، كلية الزراعة، جامعة الأزهر ، أسيوط. 


\section{الملخص}

إن التطورات التي تجري في العالم المتقدم السياسية منهها والاقتصـادية

من شأنها أن تشكل محفزًا للدول الإفريقية للقيام بإنشـاء تكتـلات اقتصـادية إقليميـة تخدم مصــالحها وتـكنها مـن مواجهة عالم اليوم الذي هو عالم التكـتلات الاقتصـادية الكبـرى، حيث أن التكامل الاقتصـادي أصبح اليوم وسيلة متفقـً عليها من قبـل المهتمين بموضـوع التتميـة، باعتبارهـا الوسـيلة الأكثر ضـــانًا للوصول إلى مسـتويات معتبـرة مـن التتميـة الاقتصـادية، وزيـادة رفاهيـة الشعوب مهمـا اختلفت الطرق والأساليب والمفاهيم المسـتخدمة والمعبرة عن هذه الوسيلة.

لذا فإن التكتلات الاقتصادية بين الدول الإفريقية تستطيع أن تواكب روح العصـر وذلك يتطلب تتمية الموارد البثـرية وتكوين المهارات و التقليـل مـن درجـة الاعتمـاد على المسـاعدات الخارجيـة و الـعـل على نبذ الخلافات الناشئة بين الدول النامية، و اتخاذ خطــوات جـادة نحـو بنــاء المؤسســات الديمقراطية ، باعتبارها الطريق السـليم للوصول الى الاستقرار السياسي وصـيانة المكاسب.

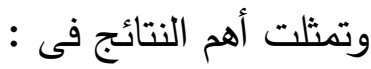


ا-قـامت التكتلات الاقتصادية فى ظل التدهور الاقتصادى للدول الأفريقية

على أساس تتمية دول أفريقيا والتباين ما بين الدول ثقافيًا وايدلوجيًا واختلاف العقائد ما بين الفكر الراسمالى والغربى والثيوعى الشرقى •

ץ-تعـتبر التكتلات الاقتصادية خطوة مهمة وضـرورية نحو تحقيق التكامل

الإقليمسى.

r-إن التكامل الاقتصادى أصبح اليوم وسيلة متفقًا عليها من قبل البـاحثين باعتبارها الوسيلة الأكثر ضمانًا للوصول إلى مستويات معبرة عن التتمية الاقتصادية وزيادة رفاهية الشعوب .

ع-تمكنت الدول الإفريقية من إنشاء تكتلات اقتصادية لها برامج وسـياسات

ومؤسسات تهدف إلى تحقيق أهداف الجماعة الاقتصادية الإفريقية عبر مـراحلها ولكنها تسير ببطء

ه-أن الـعديد من الدول الإفريقية تتمتع بالعديد مـن موارد طبيعية متتوعة والموقع الجغرافى الاستراتيجى يمثل فرصة لنجاح تجارب تكملية بين العديد من الدول منها. 
7-هناك دور كبير تقوم به التكتلات الاقتصادية فى تحقيق السـلم لأمن الإقريقين وتعتبر الايكواس هى الرائدة فى هذا المجال حيث أنها انشـات آلية بالايكموج تقوم بإحلال السلم بل وفرضـه.

الكلمات المفتاحية : الدوافع، التكتلات الاقتصادية، الدول الأفريقية.

\section{Abstract}

The developments taking place in the developed world, including political and economic will serve as a catalyst for African countries to undertake the establishment of regional economic blocs serve their interests and enable them to cope with today's world is a world of major economic blocs, as economic integration has become today an agreed upon by those interested in the topic of development, as the surest way to reach significant levels of economic development and increase the welfare of peoples, regardless of the different methods, methods and concepts used and expressed by this method.

\section{مقدمة}

شهدت القارة الإفريقية توجهاً كبيرًا نحو تكوين تجمعات إقليمية اقتصادية فاعلة، وتوجهًا آخر يهدف لتفعيل المنظمات الإقليمية الاقتصادية الأخرى القائمة 
مجلة البحوث والدراسات الإفريقية ودول حوض النيل - جامعة أسون - المجلد (r) - العدد (1) - يناير ( ب · م م)

فعلا فى القـارة الإفريقية وذلك لمـواجهة التحديات الجديدة التى تلوح فى أفق القارة الإفريقية، والتى ربما تبشر بمزيد من التهميش الاقتصادى للقارة الإفريقية ومواجهة تحديات وتداعيات العولمة الاقتصادية والاجتمـاعية والسياسية ولمواجهى هذه التحديات القادمة(').

فأصبح مـن المعروف أن أهم خصائص النظام العالمي الجديد هو الاتجاه المتزايد نحو تكوين التكتـلات الاقتصـادية العملاقة ليكون نطاقًا تتضاءل فيه أهمية الاقتصاد الذي يعمل بمفرده في الدولة الواحدة عند رسم السياسـات الاقتصادية التي تتعامل مع العالم الخارجي، بل يحل محله في هذا المجال الإقلـيم الاقتصادي للحصول على أكبر مكاسب مدكنة من التجارة الدولية وتدفقات الاستثمار وتتسيق لوائح السياسات الاقتصادية داخليًا و خارجيًا (؟). فموضوع التكتلات الاقتصادية بمختلف أنواعها واققًا ملمسوسًا ومتغيرًا هامًا من متغيرات النظام العالمي الجديد ,إذ مر الاقتصاد العالمي بمرحلة مـهمة تتمثل في

( (1)فرج عبد الفاح فرج، الاقتصاد الإفريقى من التكامل الإقليمى إلى العولمة ، دار النهضة العربية،

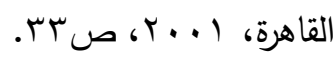
(Y) (Yحمد محمود الإمام، تجارب التكامل العالمية ومغزاها للتكامل العربي، القاهرة، مركز دراسات الوحدة العربية،، ع . . r ، ص • 9. 
زيادة درجة الانفتاح الاقتصادي الذي جعل العديد من الدول تتعاون فيـما بينها في إطار اتفاقيات اقتصادية ذات أثكال مختلفة لتتوسع فيما بعد إلى تكتـلات اقتصادية. وقد سعـت الكثير من الدول الإفريقية إلى تـعزيز علاقاتها وتضافر جهودها على المستوى القاري سواء في شكل اتفاقيات ثنائية أو متعددة الأطراف أو بتثكيل مؤسسات استراتيجية .إذ شتهدت القارة ميلاد العديد من التكتلات الاقتصـادية داخل الآقاليم الفرعية والتي كانت تهدف إلى تلبية طموحات وآمال الثعوب والتغلب عـلى الظروف الاقتصادية والاجتماعية الصعبة عبر التعاون والتكامل الاقتصادي .فأهم التكتلات الاقتصادية التي شهدتها القارة الافريقية والتي كان لها الدور البارز في النهوض بالتتمية الاقتصـادية للدول الآعضاء، فقد تم تحديث وتطـوير منظـة الوحدة الإفريقية عبر تكوين الإتحاد الإفريقى الذى تم إقراره فى قمة لومى الأفريقية فى يوليو من العام . . . بم، وانبـثاقه إلى حيز الوجود عبر الإعلان عن قيامه فى قمة سرت الثانية بلبيبيا فى مارس من العام I +. بم. مشكلة البحث:

قد ظهـرت عدد من التكتلات الاقتصادية فى القارة الإفريقية مثل تجمع دول الساحل والصحراء، ومجموعة التتمية لجنوب أفريقيا، والسـوق المشتركة للشرق 
والجنوب الأفريقى، والتجمع الاقتصـادى لدول غرب أفريقيا مع بزوغ العولمة وأحدثت تغييرات جوهرية فى مواقع القوى التجارية فى العالم ، وينطلق البحث من التساؤل التالى ما هى دوافع التكتلات الإقتصادية فى الدول الإقريقية؟

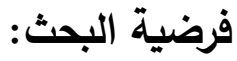

اعتمد هذا البحث على الفرضية الرئيسية التالية:

ظهور التكتلات الاقتصادية الدولية فى تحقيق التكامل الاقتصادى فى إفريقيا دفع الدول الإفريقية فى اتجاه التكتلات الاقتصادية .

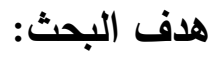

هدف البحث إلى التعرف على دور التكتلات الاقتصـادية فى تحقيق التكامل

للاقتصاد الإفريقى والمشاكل التى تواجـه هذه التكتلات .

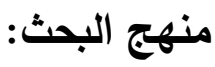

اعتمد الباحث في البحث الحالى على الدنهج الوصفي التحليلي لحداثة

المشكلة و الدعلومات الخاصة بها، وذلك للتعرف على دوافع التكتلات الاقتصادية فى

الدول الأفريقية. 


\section{الاراسات السابقة}

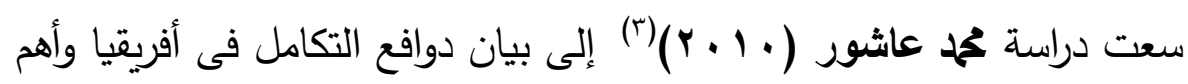

ملامح مسيرة التكامل الإقليمى التى شهدتها القارة والصعوبات والمعوقات التى واجهت جهود التكامل وصولا إلى استطلاع مستقبل جهود التكامل فى القارة فى ضوء متطلبات تفعليها.

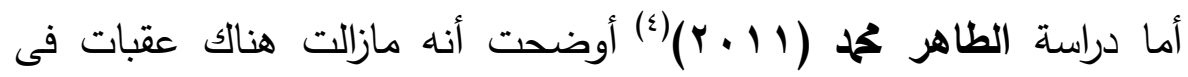

التكتلات الاقتصادية والسياسية للإسهام فى تتمية أفريقيا اقتصاديًا وسياسيًا فى سبيل تحقيق استقلال دولها من التهميش السياسى والاقتصادى العالمى على القارة الأفريقية

ومازالت التبعية الاقتصادية للقارة تعتمد على دول العالم الأول التى تتدخل فى الثؤون الاخلية لدول القارة وبذلك عملت على فثل التكتلات الاقتصادية داخل القارة

(r) (rحم عاشور مهذى، مستقبل التكامل الإقليمى فى افريقيا : قراءة فى ضوء الدوافع والواقع

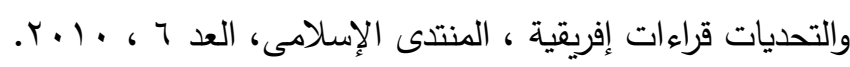

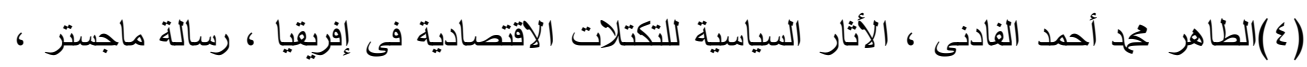

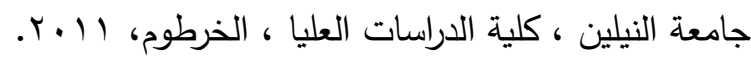
$(M \cdot)$ 


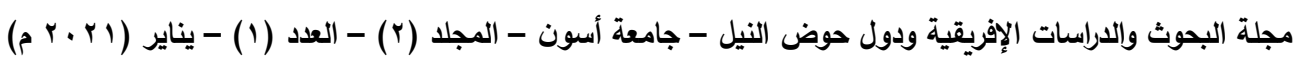

الإفريقية وأصبحت بعيدة المنال فى ظل التطورات الدولية وتماسك دول الغرب، وأصبحت التكتلات العالمية تزداد يوما بعد يوم ومازالت أفريقيا فى المربع الأول التى انطلقت منه فى الثمانينات، وتوصلت الدراسة إلى أن التكتلات قد قامت فى ظل التدهور الاقتصادى للدول الأفريقية على أساس تتمية دول أفريقيا والتباين ما بين الدول ثقافيًا والهوة الإيديولوجية واختلاف العقائد ما بين الفكر الرأسمالى والغربى والثيوعى الثرقى مما أدى على تباين فى الاقتصاد الثرقى أم الغربى واختلاف الأنظمة الحاكمة ما بين رأسمالية واشتراكية فى ما بين القيادات الحاكمة أدى لعدم انسجام وتوحيد الدول فى عملية التكتلات ما بين شعوب المنطقة.

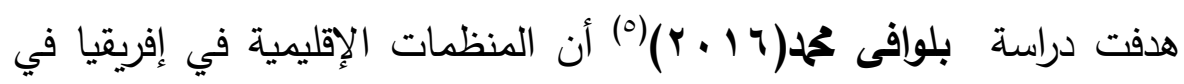
اهتمام متزايد بإقامة تكتلات اقتصادية نقدية خاصة بعد الحرب العالمية الثانية، حيث تعتبر دول قارة إفريقيا أكثر الدول تجربة في مجال إقامة مشروعات التكامل والاتحادات الاقتصادية والنقدية وتطرقت إلى مزايا ودوافع التوجهات القطرية للدول الإفريقية والتقرقة بين الدوافع الاقتصادية والدوافع السياسية، كما تتاوات أهم المجموعات الاقتصادية والنقدية وواقع التكامل الإقليمي في إفريقيا ومعوقاته.

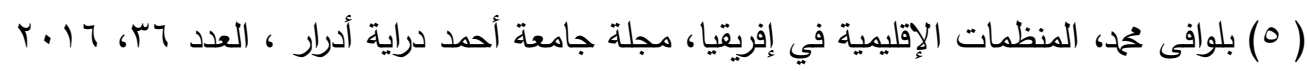

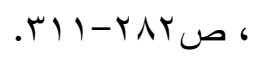


وتوصلت دراسة هويدا عبد العظيم (1 (Y) (†) إلى تسليط الضوء على التكتلات الاقتصادية الإفريقية: التبادل التجاري الضرورة التتموية. وتتاولت عدد من محورين رئيسين وهما: المحور الأول: التكتلات الاقتصادية في افريقيا: وهناك سبعة تجمعات إقليمية رئيسية في افريقيا وهي، الاتحاد المغربي العربي، سوق الشرق والجنوب الافريقي " الكوميسا"، تجمع الساحل والصحراء، الاتحاد الاقتصادي لدول وسط افريقيا الايكاس" المقر ليبرفيل" الجابون، ECOWAS تشأت الجماعة الاقتصادية لدول غرب افريقيا، تجمع السادك، سوق شرق افريقيا. المحور الثاني: أوجه التعاون والتبادل التجاري العربي الافريقي حيث تعتبر افريقيا الامتداد الإقليمي والجغرافي والاستراتيجي للدول العربية سواء في شمال افريقيا أو في منطقة الخليج العربي، ولهذا فإن وضع استراتيجية عربية طموحة لتعزيز الشراكة العربية الافريقية لم تعد مجرد خيار، في ظل التدافع العالمي والخطط التي تعد للسيطرة على أسواق افريقيا الواعدة ومواردها الطبيعية المتتوعة. واختتم المقال موضحاً أن الزراعة في افريقيا تتمتع بإمكانيات نمو كبيرة، ولكنها تعاني من غياب استراتيجية فيما يخص الموارد المالية والوسائل الفنية، ويمكن سد جزء من هذه الفجوة بالتعاون بين الدول العربية والدول الافريقية لصالح الطرفين، وذلك عن طريق شراكة مفيدة للطرفين يفرضها وجود فرص (ج)هويدا عبد العظيم، التكتلات الاقتصادية الافريقية: التبادل التجارى ضرورة تتموية، مركز الخليج

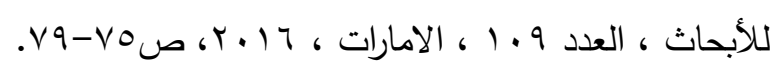


كبيرة للتكامل بين المنطقتين، بتوفير الموارد المالية والوسائل الفنية من الجانب العربي وتوفير المياه والأراضي واليد العاملة من الجانب الافريقي.

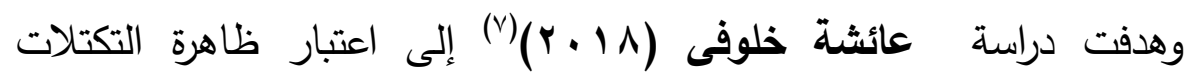

الاقتصادية من أكبر الظواهر العالمية اللافتة للانتباه خاصة بعد انتقال هذه التكتلات من مراحل الانتثار إلى مراحل تعميق العلاقات الاقتصادية بين أعضائها كما هو حال الاتحاد الأوروبى، فلم تعد التكتلات حكرًا على قارة أو مجموعة دول أو إقليم بعينه وإنما انتشرت فى جميع مناطق العالم وبمختلف الأشكال ، وأيا كان شكل التكتلات فإن لها تأثير واضح على جوانب حركة التجارة الدولية، ويهذف هذا البحث إلى إبراز هذا التأثير من خلال التطرق إلى هذه الجوانب التى تتمثل فى حرية التجارة على المستوى العالمى، اتجاهات التجارة الدولية، والتوزيع الجغرافى، ومحاولة إسقاط هذه الجوانب على حالة الاتحاد الأوربى الذى وصل على مراحل متقدمة من عملية التكتل مما يجعل تأثيره على تجارة الدول الأعضاء وغير الأعضاء واضح. يقسم هذا البحث إلى:

(V) عائشة خلوفى، انعكاسات الاتجاه المتزايد نحو التكتل الاقتصادى الإقليمى على حركة التبادل

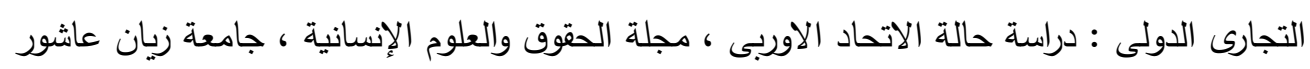

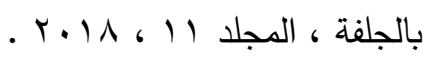
$(M r)$ 


$$
\text { المبحث الاول: مفهوم التكتلات الاقتصادية. }
$$

المبحث الثانى:التكتلات الاقتصادية الإقليمية لقارة إفريقيا.

المبحث الثالث: دوافع التكتلات الإقتصادية في الدول الأفريقية.

\section{المبحث الأول: مفهوم التكتلات الاقتصادية}

إن ظـاهرة التكتلات الاقتصـادية ليست بالظاهرة الجديدة إلا أن ظهورها

كتجربة اقتصادية كانت بعد الحرب العالمية الثانية اتخذتها مجموعة من الدول سواء كانت نـامية أو متقدمة، رأسمـالية واشتراكية، وهذا لمواجهة مختلف التحولات التى شتتهدها العالم فى تلك الفترة ، فظهرت هذه التكتلات كنتيجة للقيود فى العلاقات الدولية، وكمحاولة جزئية لتحرير التجارة بين عدد من الدول، فظهرت التكتلات الاقتصادية فى صورة مشروعات فردية قدمتها أمريكا للدول الأوروبية ودول الشـرق الاوسط مثل مشروع "مرشال" الذى يهدف على تقديم المساعدات الاقتصادية المصحوبة بشـروط سياسية وعسكرية ، وقـد كانت شعوب قارة أوربا أول من ساهم 
مجلة البحوث والدراسات الإفريقية ودول حوض النيل - جامعة أسون - المجلد (r) - العدد (1) - يناير ( ب · م م)

فى نشأة التكتلات وذلك بحكم ما تعرضت إليه هذه الشعوب مـن أزمات اقتصادية نتيجة للحرب العالمية الثانية(^).

فيعرف التكتل الاقتصادى بأنه تجمعات إقليمية يتم أنثاؤها بمـوجب اتفاق

يُعد بين عدة دول مختلفة تترابط علاقاتها بروابط التضامن والجوار لحماية مصـالحها

وحفظ السـلم والأمن الدوليين وفقا للأهداف والمبادئ التي تقوم عليها الأمم المتحدة(9).

ويعرف "بيلا بالاسا Bella Ballassa" التكتل الإقتصادي على أنه عملية

وحالة، فبوصفه عملية فإنه يشمل الإجراءات والتدابير التي تؤدي إلى إلغاء التمييز بين الوحدات المنتمية إلى دول قومية مختلفة، وإذا نظرنا إليه على أنه حالة فإنه في الإمكان أن تتمثل في انتقاء مختلف صور التقرقة بين الإقتصـاديات القومية(·'). يعبر التكتل عن درجة معينة من درجات التكامل الاقتصادى الذى يقوم بين مجموعة من الدول المتجانسة اقتصـاديًا وجغرافيًا وتاريخيًا وثقافيًا واجتماعيًا، والتى (^)حسن مصطفى سلامة، الجماعة الاقتصادية الإفريقية ، قراءة قانونية "السياسة الدولية ، العدد rا

(9)عبد السلام صالح عرفة، المنظمات الإقليمية والدولية، الدار الجماهيرية للنشر والإعلان، طرابلس،r99 (، ص101r. (· (1) بيلا بلاسا، نظرية التكامل الإقتصادي، ترجمة رشيد البراوي، دار النهضة العربية، القاهرة، 
تجمعها مجموعة من المصالح الاقتصادية المشتركة، بهدف تعظيم تلك المصالح وزيـادة التجارة الدوليـة لتحقيق أكبر عائد ممكن ثم الوصول إلى أقصى درجة من

الرفاهية الاقتصادية لشعوب تلك الدول(').

فالتكتل الاقتصادى وسيلة تلجأ إليها دول مسعينة ضمن منطقة معينة لتحقيق

أهداف معينة ومتعدة، ولكن ترتكز جميعها حول دفع عجلة النشاط الاقتصـادى فى الاتجاه الصحيح وبالسرعة الضرورية لتحقيق معدلات نمو طموحة يمكن أن تؤدى إلى تضـيق الفجوة الواسعة بين مستويات المعيشة فى الدول الـغنية وفى غيرها من الدول

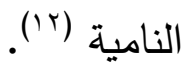

\section{خصائص التكتلات الاقتصادية وخطوات تحقيق أهدافها:}

للتكتلات الاقتصادية عدة خصائص وأهداف تسعى لتحقيقها وهى:

$$
\text { ()خصائص التكتلات الاقتصادية : }
$$

(1) (1)فرج عبد الفتاح فرج، إمكانيات التعجيل بتتفيذ الجماعة الاقتصادية الأفريقية فى ظل الاتحاد الأفريقى ، بحث مقدم لمؤتمر الاتحاد الافريقى، ا ... ب، صسب. (r ( )مفتاح سويسى الفرجانى، الاتحاد الإفريقى فى ظل التكتلات الاقليمية والدولية، بحث مقدم للندوة

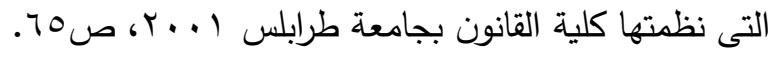




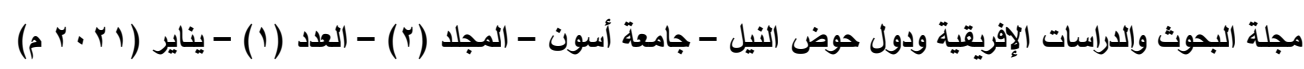

1-حرية التتقل للسلع والخدمات والأشخاص ورؤوس الأمـوال والاستثمار بين الدول المتكتلة.

ب-قوتها فى التفـاوض على المستوى الدولى هذا للدفاع عن مصالحها ضد التكتلات الاقتصادية الأخرى.

ب-تتصف التكتلات الاقتصادية بحجمها الضـخم من حيث مواردها وإنتاجها واتساع أسواقها الاستهلاكية والإنتاجية وتتوع هياكلها الاقتصادية ومواردها وكثافة حجم سكانها.

ع-ارتفاع نسبة التجارة البينية من مجمل تجارتها الخارجية وهـذا ما يجعلها

تخفض من التبعية الاقتصادية، أو تكون لها درجة عالية من الاستقلالية الاقتصاجية بالنسبة للدول الخارجة عن المنطقة التكاملية وهذا ما يؤدى إلى الارتباط بين الدول المتكتلة من خلال تشابك اقتصادياتها وأسواقها.

ه-توفير مزايا ومكاسب تعجز الدولة منفردة عن تحقيقها. 
ج-المنافسة الحرة بين الدول المتكتلة فى المنطقة التكاملية ولها سياسة

تجارية موحدة تجاه الدول الأخرى خارج نطاق التكتل(r').

\section{أهداف التكتلات الاقتصادية: - 2 - 2}

تسعى التكتلات الاقتصادية تحقيق الأهداف التالية:

1-الالتزام بالمـنافسة الحـرة داخل المنطقة التكاملية وهذا يستدعى منح

المنتجين تقسيم الأسواق وتحديد الأسعار •

r-التعاون مع الدول الأعضاء على تحقيق التوازن فى مـتوازين المدفوعات

بالنسبة للـدول التى تحقق عجز فى موازينها خاصة فى بداية قيام التكتل الاقتصادى.

ب-أن تكون لدول التكتل سياسة تجارية موحدة تجاه العالم الخـارجى مع

تطوير هذه السياسة وامتيازها بالمرونة وفقًا لتطـور الأوضاع والعلاقات الدولية

الاقتصادية.

(r ( ) على عبد الله المناعى، التكتلات الاقتصادية ودورها فى تطوير البنية، مركز البحرين للدراسات

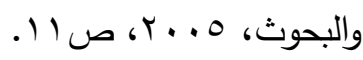


مجلة البحوث والدراسات الإفريقية ودول حوض النيل - جامعة أسون - المجلد (r) - العدد (1) - يناير ( ب · م م)

ع -إنشاء بنك الاستثمار الموحد خاص بدول التكتل يهدف إلى تـمويل

الصناعات التى يجب إقامتها لاستغلال الإمكانات الصناعية المتاحة فى هذه الدول

وإعادة بناء الصناعات القائمة مع صرارعات التقدم العلمى والتكنولوجى الحديث(؛ ().

ه-إلغاء القيود على حركة السلع وعناصر الإنتاج بين الدول الأعضاء مع

خضوع تحركات الأشخاص للقوانين السائدة فى كل من هذه الدول.

7-يجب ألا تقتصر وظيفة الإدارات والأجهزة المختلفة على إعداد خطط

التنسيق وإنما يجب أن تمتد لتشمل تتبع التتفيذ وتقديم النتائج.

V-إنشاء الصندوق الموحد للتعـاون الاجتماعى بين دول التكتل يكون هدفه

تدريب العمال وتأهيلهم تأهيلا تكنولوجيا.

(ع ()عبدالرحيم يونس، دور التجمعات الإقليمية فى دعن التكامل الاقتصادى الأفريقى، دراسة على

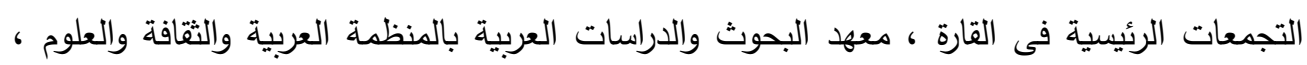




\section{المبحث الثانى: التكتلات الاقتصادية الإقليمية لقارة إفريقيا}

شـملت ظـاهرة التكتلات الاقتصادية العـالم بقـاراته المخـتلفة كما أنها شملت القارة الافريقية بمختلف أقاليمها، ووزعت بشكل متفرق على كل من شمال، شرق وسط وغرب افريقيا .وهو ما ذهبت إليه اللجن الاقتصادية لإفريقيا التابعة للأمم المتحدة وأقره ميثاق منظمة الوحدة الافريقية بضـرورة تعزيز التعاون الاقتصادي بين الدول الأعضاء واتباع أسلوب التجمعات الإقلـيمية الفرعية للتعامل مع الأوضاع الاقتصادية وتحقيق التتمية وللتغلب على مشكلة العدد الكبير من الدول الفقيرة والأسواق صغيرة الحجم المنتشرة في إفريقيا، عملت دول المنطقة منذ مطلع السبعينيات من القرن الماضي على تأسيس العديد من منظمات التكامل الاقليمية(10). يمكن تقسيم الدول الافريقية وفق اتفاقيات التجارة الحرة بين الأقاليم المختلفة إلى تجمعات مختلفة وهي المجموعة الاقتصادية لدول غرب افريقيا(ECOWAS)، ومجموعة دول جنوب افريقيا للتمية(SADC)، واتحاد المغرب العربي (AMU)، والمجموعة الاقتصادية لدول وسط إفريقيا (ECCAS )، والسوق المشتركة لدول شرق

(0 1) عبد الوهاب الآمين، بثير طاهر فريد، التجارة العربية الافريقية ودورها في دعم التتمية في الآقطار الإفريقية جنوب الصحراء، المصرف العربي للتنمية الاقتصادية في إفريقيا، مركز المعرفة للاستشارات والخدمات التعليمية، الدنامة -البحرين، 9 .. ؟، صب ا. 
وجنوب افريقيا(COMESA)، كما تثعبت وتفرعت عن هذه التكتلات، تكتلات اقليمية أصغر في منطقة جنوب الصحراء، تضم UEMOA ،MRU، ويتبعان تجمع ECOWAS تكتل ECEM و CEMAC ويضمان دول أعضاء في SADC ECCAS,COMESA IGAD و و IOC ويضمان الدول الأعضاء في COMESA وتأسست أيضا SACU وتضم بعض دول SADC (17)

وللإثارة فإن التجمع الاقتصادي لدول إفريقيا AEC هو التكتل الوحيد الذي يضم جميع دول القارة.

أ) أتجمعات شرق وجنوب إفريقيا.

\section{1- تجمع شرق افريقياEAC}

تم التوقيع على معـاهدة للتعاون الشرق الافريقي بأوغندا في VT97 من طرف أوغندا، كينيا وتنزانيا .وقد أنثئت بمقتضاها جماعة شرق افريقياEAC وأرست المبادئ التي أخذت بها منظمة الخدمات المشتركة لثـرق افريقيا ومقرها في

(9) عبد الوهاب الآمين، بثير طاهر فريد، التجارة العربية الافريقية ودورها في دعم التتمية في الآقطار

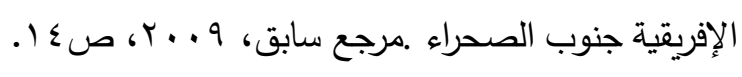


أروشا(تنزانيا)، ودخلت حيز التنفيذ في VTو 9 ووضعت الاتفاقية أسس السوق المشتركة لشرق افريقيا ومدتها 10 سنة وكان هدفها هو إقامة اتحاد اقتصادي .غير أن هذه الخطوة لم تكلل بالنجاح وانهارت الجماعة .وإلى غاية سنة 999 اتم التوقيع على معاهدة لإعادة بناء الجماعة لتدخل حيز التنفيذ بعد اسـتكمال الدول الثلاث التصـديق عليها في منتصف (y')(على أساس تشكيل سـوق مشتركة. يضم التجمع خمس دول وهي :كينيا، تنزانيا، رواندا، بورندي .والهدف منه

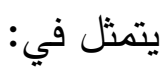
إقامة المؤسسات المالية والنقدية الافريقية.

إقامة سوق مشتركة وتيسير إجراءات السفر والتنسيق في مجال التعريفات

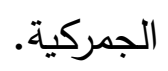$$
\text { تعزيز قيم الوحدة الافريقية. }
$$

حرية تـقل الافارقة بين الدول الافريقية.

( V) ( اليفة مصمونى، التكامل بين المنظمات الاقليمية الفرعية الافريقية ودوره في تحقيق الوحدة

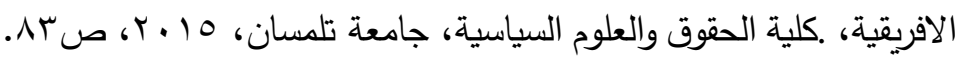




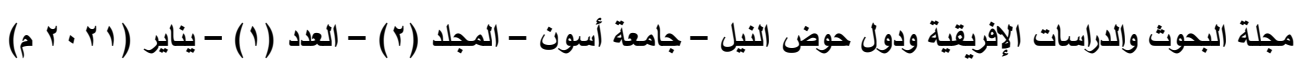

• ترشيد المجموعات الاقتصـادية الافريقية وذلك عبر إزالة جوانب التداخل والازدواجية بين المجموعات الاقتصادية الافريقية.

\section{ب- السوق المشتركة لدول شرق وجنوب إفربقيا (الكوميسا COMESA)}

تعتبر أحد أعمدة المجموعة الإقتصادية الإفريقية .وقد ظهرت السوق

المشتركة لدول شرق وجنـوب إفريقيا على مـراحل منذ عام • 197 إلى أن تحققت بالصورة التي نراها اليوم في شكل منظمة الكوميسا .وقد عقد أولا اتحاد جمركي بين غينيا وأوغندا، ثم عدلت أحكامها(^^).

ففي مارس 9 ا اتم التوقيع على إعلان لوزاكا المتضــن مشروع إقامة وحدة اقتصادية بين دول الإقليم، وفي ديسمبر (919 اتم التوقيع على معـاهدة إنشاء منطقة التجارة الحرة التفضيلية بعـاصمة زامبيا لوزاكا، ودخلت المعاهدة حيز التتفيذ في r 191، ثم تحولت هذه المسعاهدة لتأخذ شكل تجمع الكوميسا في س991 ، وتم طرح فكرة تحويـل منطقة التجارة التفضيلية إلى سـوق مشتركة، ليتم التوقيع على الـمعاهدة الجديدة لسوق الكوميسا الإقريقي في ؟9 أفي ليونجوي عاصمة مالاوي(9') ،وتضم

(1 ( )جمال الدين أبو بكر ، التكامل الاقتصادي العربي والمشكلات التي تواجهه، القاهرة، دار النهضة

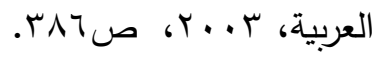

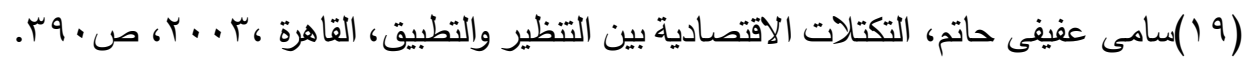


حاليا 91 دولـة واقعة في أنه في جنوب وشرق إفريقيا، وتسعى الدول من خلال هذه

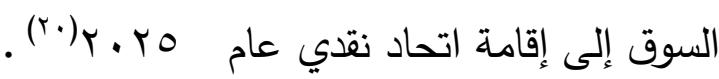

وفى عام . . . ت تم التحرك نحو إقامـة منطقة التجارة الحرة والقضاء على

كافة القيود الجمركية وغير الجمركية والاتفاق على إنثـاء الاتحاد الجمركي بحلول ع ... بهدف وضع تعريفة جمركية موحدة اتجاه السلع الواردة من الدول غير الأعضــاء، قد تأخرت هذه العملية إلى غاية 9 . . ؟.

\section{ومن أهدافها الرئيسية:}

تشـيع البحث العلمي والتطوير •

السـي إلى تــمية الدول الأعضاء عن طريق تشجيع التتمية المتوازنة والمتناسقة بين هيكل انتاجها وتسويق منتجاتها.

تعزيز التعاون والتتمية في كافة قطاعات النشاط الاقتصادي لرفع المستوى المعيشي. التعاون لتعزيز السلام والآمن والاستقرار بين الدول الآعضاء.

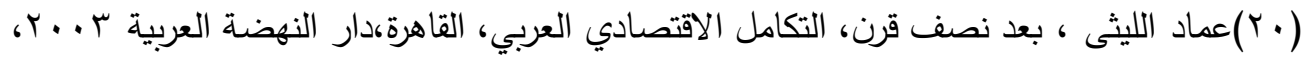
ص.A. 
التعاون في توثيق العلاقات بين السـوق الاقريقية المشتركة وباقي دول

$$
\text { ومناطق العالم، وتبني مواقف مشتركة في المحافل الدولية. }
$$

دفع عجلة التنمية المشتركة في كافة مجالات النشاط الاقتصادي( الزراعة، والآمن الغذائي، والنقل والمواصلات، والخدمات، والصناعة، ,الطاقة، ,الثروة

$$
\text { الحيوانية). }
$$

\section{الهيئة الحكومية الدولية المعنية بالتنمية(IGAD)}

تأسست عام 997 هي هيئة ترعى التعاون والتتكامل الإقليمي فى منطقة

شرق إفريقيا، وتعوض“ إيجاد "الهيئة الحكومية للتمـية ومواجهة الجفاف (IGADD) التى تم تأسيسها فى عام 1917 من جانب ست دول تعانى من الجفاف فى شرق إفريقيا، وهى جيبوتى وإثيوبيا وكينيا والصومال والسودان وأوغندا، ثم انضمت إليها إريتريا كعضو سابع بالمنظمة. ب)تجمعات غرب إفريقيا 


\section{UEMOA}

تأسس عام \199 ويـهدف إلى تحقيق الاندماج الاقتصادي للدول الآعضاء الثمانية في سوق اقتصادية منفتحة وهم البينين، بوركينا فاسو، الكوت ديفوار، غينيا بيساو، مالي، النيجر، السنغال والطوغو .وقد أسست هذه المجموعة عملة خاصة بها وهي ولها بنتك مركزي يدير هذه العملة .وبالرغم من صغر حجم هذه المجموعة والتي لا تمثل إلا • (\% من سكان القارة و ؛ من سكان القارة فقط من إنتاجها، إلا أن نسب النمو الاقتصادية العـالية التي سجلتها أغلب بلدان هذه المجموعة على غرار الكوت ديفوار والسنيغال جعلتها من المجموعات القوية في المنطقة.

\section{ECOWAS" "جماعة غرب إفربقيا الاقتصادية}

تعود فكرة إنشاء مجموعة غرب افريقية إلى العام £971 على أيدي الرئيس الليبيري وِليـام طوبمان الذى أطلقها بعدما وقع في فبراير 1970 على اتفاق يضم إلى جانب بلاده؛ كلا من الكوت ديفوار(ساحل العاج )وغينيا والسيراليون ـ لكن التجربة لم تقوى أمام الآزمات الحدودية ومصاعب التخخلات الغربية ففشلت سريعا . ومع تسلق الجيل الثاني من القادة القادمين إلى السلطة بواسطة الانقلابات العسكرية 
مجلة البحوث والدراسات الإفريقية ودول حوض النيل - جامعة أسون - المجلد (r) - العدد (1) - يناير ( r · م م)

أعيد استئناف المشروع على يدي الجنرال ياكوبو دان يوما جوون (رئيس نيجيريا ) والجنرال اكنا ناسِينْخْ يِي أيَادِيمَا (رئيس التوغو)؛ اللذين تزعما جهود قيام الاتحاد وجمع مساهمات اثتتي عشرة دولة في المشروع .فخصصا أول اجتماع بالعاصمة الطوغولية

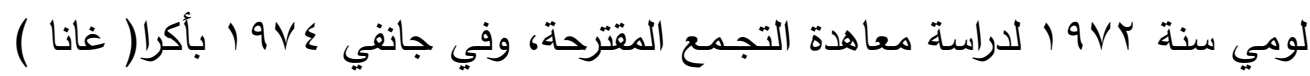
انعقد اجتماع الخبراء للنظر في الجوانب المؤسسية، وفي جانفي 9 ا9بونروفيا عقد اجتماع للحكومات لإقرار مضامين المعاهدة المقترحة، وأخيرا، وقعت أربعة عشر دولة غرب افريقية على معاهدة المجموعة الاقتصادية لدول غرب أفريقيا فى $19 \vee 0$

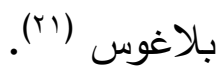

وتتكون المجموعة من : داهومي، غامبيا، غانا، غينيا، ساحل العاج، ليبيريا، مالي، موريتانيا، النيجر، نيجيريا، السنغال، سيراليون، الطوغو، بوركينافاسو وهنا اتجهت دول غرب افريقيا إلى إقامة عـلاقات اندماجية متكافئة فيما بينها بهدف تبادل المصـالح الاقتصادية والاستفادة من الموارد الطبيعية والبشرية المتاحة، وتوحيد القواعد والإجـراءات مما ي ؤدي إلى زيادة الإنتاج وتطوير التبـادل التجاري بين بلدان المجموعة الاقتصادية، هذه الآخيرة كانت تهدف إلى إنشاء سوق

(Y)(ببيد إميجن سالم، المجموعة الاقتصادية لدول غرب افريقيا " الايكواس، مقومات النجاح وقيود

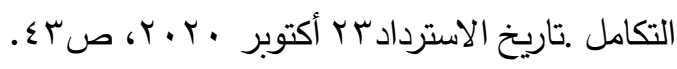


موحدة، لزيادة التبادل للسلع والخدمات، وتحرير انتقال عوامل الإنتاج، وتتسيق السياسات الاقتصادية، إضافة إلى التخفيض التتريجي والمستمر للتعريفات الجمركية، وإزالتها نهائيا بحلول عام 9 19 1 وتطبيق تعريفه موحدة بحلول عام • 99 .

\section{ب- الاتحاد الجمركي الاقتصادي لغرب إفربقيا}

أنشئ عام ع 19 1 ، و يتكون من :داهومي، ساحل العاج، مالي، موريتانيا، النيجر، السنغال، بوركينافاسو، ويهدف إلى تحقيق التنمية الاقتصادية في المنطقة و ذلك بتحرير المبادلات التجارية، إقامة اتحاد جمركي(r؟).

\section{ج) تجمعات شمال ووسط إفريقيا}

\section{1-اتحاد دول إفربقيا الوسطى.}

أنشئ عام 971 بين جمهورية إفريقيـا الوسطى، تشاد، الكونغو، والهدف من إنشائه تحقيق تعاون إقليمي، إقامة سوق مشتركة، تتمية الاتصالات، والتوزيع العادل للمشاريع، وإلغاء جميع الضرائب على التجارة الداخلية(r؟).

(IT) (Y) المبد المطب عبد الحميد، النظام الاقتصادي العالمي الجديد وآفاقه المستقبلية بعد أحداث

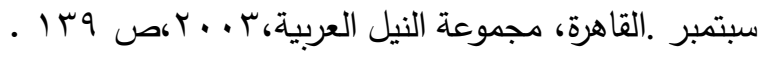




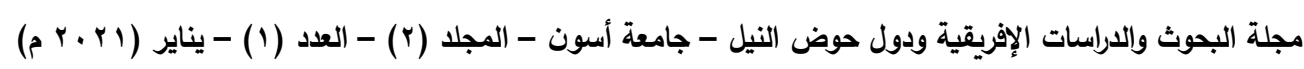

إضافة إلى الإتحاد الجمركي الاقتصادي لإقريقيا الوسطى الذي أنشأ عام

ء 19 و يهدف إلى التعاون النقدي و تحقيق التتمية الاقتصادية، و الوصول إلى

سوق مشتركة بتعريفة جمركية موحدة

r-اتحاد المغرب العربي.

أنشئ فى 1919 1، ويضـم كل من الجزائر، المغرب، تونس، ليبيا، موريتانيا والهدف من إنشائه :

• تحرير انتقال رؤوس الآموال بين الدول الآعضاء

تحقيق التعاون بين الدول الأعضاء

•تـسيق و إتباع سيـاسات مشـتركة في المجـالات الاقتصادية والاجتماعية و

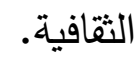

تحقيق التتمية المشتركة.

تتسيق السياسات النقدية وتتسيق أنظمة الرقابة على الصرف.

(rT) (Yحمح محمود الإمام، تجارب التكامل العالمية ومغزاها للتكامل العربي، القاهرة، مركز دراسات

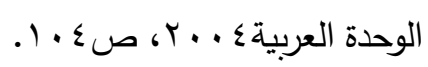




\section{ب-المجموعة الاقتصادية والنقدية لأفربقيا الوسطىCEMAC}

تأسست فى ـ99 1991991 أتسمى بالاتحاد الجمركي والاقتصادي لدول أفريقيا الوسطى UDEAC

وتضم 7 دول من أفريقيـا الوسطى وهي الكامرون، جمهورية أفريقيا الوسطى،

الكنغو، الغابون، غينيا الاستوائية والتشاد .كما تعتبر هذه المجموعة ضعيفة من حيث نسب النمو المحققة في أغلب أعضائه إذ أنها لا تمثل إلا ؟\% من سكان القارة و ؟\% فقط من حجم الانتاج فيها.

\section{المبحث الثالث: دوافع التكتلات الإقتصادية في الدول الأفريقية}

تعـاني معظم الدول النامية من اختلالات هيكيلية في إقتصادها الوطني ويرجع ذلك للعديد من الأسباب أهمها(گ؟): - - - عدم الاستخدام الأمثل للموارد المتاحة.

r - - إنخفاض الإنتاجية الحدية للـعامل ورأس المال.

(؟)فؤاد أو ستيت، التكتلات الإقتصادية الإقليمية والعالمية: (المزايا والمعوقات)، المجلة العلمية

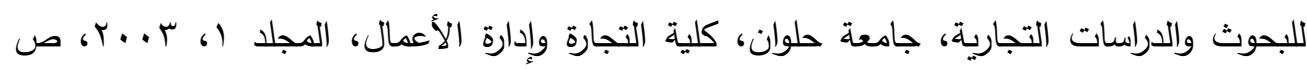
$\cdot Y \cdot \Lambda \cdot r \cdot V$ 


\section{r- عدم توافر التكنولوجيا المناسبة ومراكز البحوث المساندة.}

ع - التركيز على سياسة إحلال الواردات وغيرها من السياسات

\section{الإقتصادية.}

ومن أهم الدوافع والمحفزات للتكامل العـربي الأفريقي وجود الكثير من الموارد

والميزات الإقتصادية للدول المعنية، ولكن نجد أن محاولة حصر المصادر الإقتصادية للدول الأفريقية يقلل من تقديرها ويستبعد ما خفى من خيرات في باطن الأرض وظـاهرها، كما أن المجهود الإنساني سيظل الطاقة المتجددة لاستكثاف المزيد من المصادر الإقتصادية وزيادة الإنتاجية أضعافًا مضاعفة، مثلما حدث في الثورة الخضراء بالدول الآسيوية وفي المجال الصنـاعي بالدول المتقدمة كذلك، فإن الإقتصـاد العالمي قد تحـول من الاعتماد على عوامل مادية بحتة إلى إقتصاد معرفي يعتمد على عوامل إنتاجية رمزية وخدمات بصورة أكبر من إعتماده على العوامل المادية، فعلى سبيل الـثال: فإن اليابان التي تعتبر في مقدمة الدول الصناعية لا تمتلك من المصادر الطبيعية الكثير، غير أن إرادة الإنسان الياباني قد استجلبت مدخلات الإنتاج غير المتوفرة لديها وحولتها إلى منتجات يضرب بها المـثل في الجودة والإتقان، واستحققت أعلى الأسعار في الأسواق العالمية، كما أن وجود خطط 
استثمارية سـوف تمثل مؤشرات أولية لمواطن هذه الميزات الإقتصادية، وستتكفل بعملية دفع النشاط التكاملي، عبر القطاع الخاص إلى الأمام لكن رغمًا عما قيل(ror). فُُصنف دول أفريقيا في مجملها في عداد الدول المتخلفة اقتصادياً؛ فبالرغم من أن القارة تستوعب rا \% من سكان العالم؛ فإنها لا تحوز أكثر من ب٪\% من الناتج المحلي الإجمالي العالمي(بr)، ونصيبها في التجارة العالمية، في مطلع الألفية الجديدة، لم يزد عن r\%؛ كما أن القارة هي الأقل فيما يتصل بنسبة الاستثمار إلى الدخل القومي قياسًا بالدول والمناطق النامية الأخرى في العالم، وطبقًا لبيانات البنك الدولي، فإن الاستثـار الأجنبي المباشر في أفريقيا لم يزد عن ا \% من الاستثار الأجنبي على المستوى العالمي. وإضافة إلى مشكلة تفاقم الفقر وتزايد التهميش واجهـت القارة مشكلات أخرى تمثّل أبعادًا للأزمات، من ذلك انتشار الأمـراض وفي مقدمتها داء الإيدز وتفاقم أعباء الديون الخارجية، وهذا ما قاد الدول الأفريقية إلى قبول التذخل الخارجي المباشر مقابل المساعدات الدولية الضرورية، وهو التدخل الذي اتخذ أبعادًا أكثر شراسة في (ro)(الأمر الجيلي الثيخ الأمين، المصرف العربي للتنمية الإقتصادية في أفريقيا (التعاون العربي

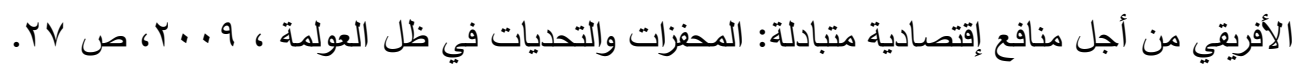

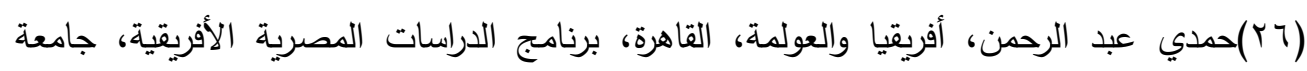

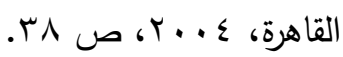


العقد الأخير من القرن العشرين، حيث لم تعد الثروط مقتصرة على الجوانب الاقتصادية بل تعدتها إلى مشروطية سياسية(rV).

وبالرغم مسن تعدد الأسـباب المسؤولة عن ضـف الدول الأفريقية في

الاقتصاد العالمي وتهميثها، ظلت الطبـيعة الانقسامية للقارة تمثل القيد الرئيس والعـبة أمام نمـو القارة وتتميتها، وفي ظل تلك الظروف وواقع التقتت الذي وُلدت فيه الدولة الأفريقية بعد الاستقلال بفعل الحدود السياسية الموروثة عن الاستعمار (^^)، سعت حكومات تلك الدول إلى تبـني خطط اقتصادية للتتمية، وعُد التكامل الاقتصادي الإقليمي فيها ولو من الناحية النظرية أحد السبل الأسـاسية لتحقيق التتمية؛ انطلاقًا من الـمزايا التي توفرها العملية التكاملية.

\section{والتي يمكن إجمالها في:}

(Y V)

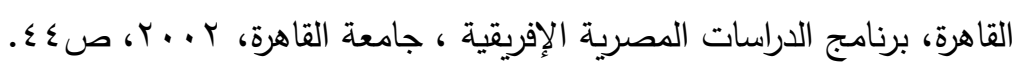
(YN) الإفريقي، 997 (1 ص ال. 
- بلـورة وحـدات اقتتصادية قـادرة على البقاء والاستمرار ، وأسـواق واسعة تسمح

باتباع آليات الإنتاج الكبير، لمعالجة قصور عوامل الإنتاج في كل دولة على حدة عن الوفاء باحتياجات المشروعات الكبرى.

- تُقدم خطط التكامل ومشاريعها الإطـار المـناسب لحثد الموارد والأسـواق، للتمكن من دخول مـرحلة التصنيع بدلًا من الاكتفاء بإيجاد الأسواق للصناعات القائمة(9+، فهو يقوم بدور القوى الـدافعة للتنمية الاقتصادية وليس مجرد أثر لها. - - تؤدي إلى المنافسة بين المنتجات والمنتجين الإقليميين، بمـا يزيد من الكفاءة الإنتاجية للمشروعات الاقتصادية ويحقق الاستغلال الأمثل للموارد. - - تمثّل عاملً للتوسع الاقتصادي للدولة المصدّرة للعمالة عبر تخفيف الضغط على سوق العمل، وتوفير دخل إضافي من خلال تحويلات العاملين بالخارج،

(Yq) ترتبط هذه المسألة بقضية اقتصادية أكبر تتعلق بما يُعرف بالأثر الإنثائي والأثر التحويلي

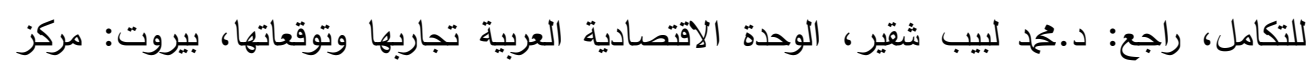

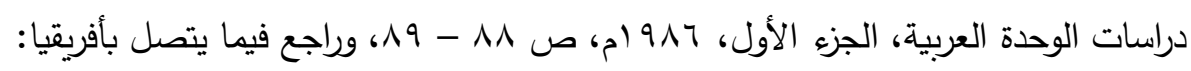
Economic Commission for Africa, op.cit, pp 11 - 12. 
كما تستفيد الدولة المضيفة للعـمالة بقدر ما تُحدثه الأخيرة من مسـاعدة في تطوير إمكانيات الـدولة المـضيفة وقدرتها التتافسية وخفض تكلفة الإنتاج(·r). - الحيلولة دون تكرار المشروعات والمساعدة على الاسـتخدام الأمثل للمـوارد والأدوات المتاحة، وتجنب إهدار الموارد النادرة وبخاصة رؤوس الأمـوال؛ حيث يتجـه رأس المال إلى حيث أفضل الفرص المالية والاقتصادية في نطاق

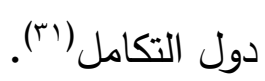
- الحدّ من تدهر المركز الخارجي للبلدان الأفريقية على الصـعيد الدولي، وزيادة قدرتها التفاوضية بشأن شروط التبادل الاقتصادي، والتي تتطلب خبرات وقدرات تتجاوز إمكانيات الدول الأفريقية فرادى. - إعادة توزيع الموارد وتوظيفها في نطاق دول الإقليم المشاركة في نطـاق التكامل كإجراء وقائي، في حالات عدم اليقين مثال ذلك استثمارات كوت ديفوار وبنين وتحويلات زيمبابوي إلى زامبيا.

(30) Mohamed Haddar, "Economic Integration In Africa From Speech To Reality" in Development And Socio-Economic Progress.( Vol.4, No.53, 1992), pp $5-6$.

(ابحمح لبيب شقير، الوحدة الاقتصادية العربية تجاربها وتوقعاتها، ج)، مركز دراسات الوحدة العربية، بيروت، بر9 اص .9.9. 
ويتقق العديد من الإقتصاديين مثل Balassa ، Viner ، Mead وغيرهم على ضرورة توافر عدة معايير تجعل التكامل الإقتصادي مرغوبًا فيه إقتصاديًا وتتمثل أهـم هذه المعايير في تشجيع درجة المنافسة واستغلال الطاقات المتكاملة في المستقبل، ضـرورة زيادة نصيب التجارة البينية بين الـدول الأعضـاء بالنسبة لتجـارتهم مع العالم مع إنخفاض مسـاهمة التجارة للناتج المحلي الإجمـالي، الأمر الذي يمكن الاعتماد عليه كمؤشر على مدى الإندماج في الإقتصاد العالمي، والإستفادة مـن مزايا إقتصاديات النطاق والتي ترجع إلى الإختلاف في أنماط السلع ولإختـلاف الأسـواق بالنسبة للسلع المنتجة وخاصة في قطـاع الصناعة، مع ضـرورة الإستمرار في تخفيض الرسوم الجمـركية، متما يؤدي بدوره إلى زيادة الرفاهية(r؟). ولبقاء واستمرار الإطارات التكاملية يجب العناية بأمرين:

أولهما: التركيز على الدور الهام والفاعل الذي تلعبه المنافسة ويـبب التركيز على تضمينها في كل الإتفاقيات.

(rr) عبدالقادر السيد متولي، الإقتصاد الدولي: النظرية والسياسيات، دار الفكر ناشرون وموزعون،

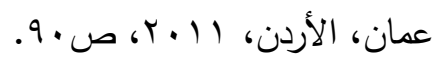




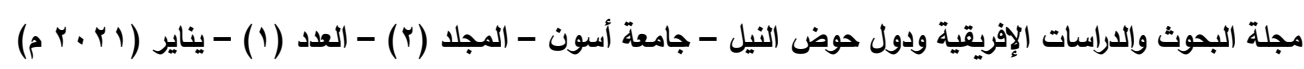

ثانيهما: ضرورة توافر آليات للتوزيع العادل للمزايا والتكاليف الناجمـة عن

الـدخول في التحالفات الإقتصادية والإقليمية، فقد تظهر بعض الآثار السلبية في المدى القصـير والمتوسط ويدخل ضـمن هذه الآليات مشكلة تسوية المدفوعات(rr). ويشير كل من "Viner" و "Mead" وغيرهما إلى أن فرض نجاح التكامل الإقتصادي يعززها الأثر الإنشائي نتيجة لزيادة حدة المنافسة بين الدول الداخلة في نطـاق الإتحاد، ومن ثم الوصول إلى مـرحلة أكثر تقدمًا من مراحل التقدم الإقتصادي مثل الإتحاد الجمركي أو الوصول إلى صـورة أعلى بين دولة نـامية أو أكثر مع إحدى أو بعض الدول الصناعية، وذلك لأن طبيعة هذه الإقتصاديات تكـون ذات طبيعة تكميلية وليست تكاملية، حيث تعتمد الدول الصناعية على إستيراد المواد الخام من الدول النامية وتعتمد الـدول النامية على الدول الصناعية في سد حاجتها من السلع المصنعة، ولا يؤثر قيام التكامل فيما بينهما إلى تغيير في نمط وتوزيع الموارد، حيث أن فرص الإستفادة من التجارة قد استنفذت فيما بينهما قبل قيام الإتحاد(๕؟).

(rr)(بدالقادر السيد متولي، الإقتصاد الدولي: النظرية والسياسيات، مرجع سابق، ص (9).

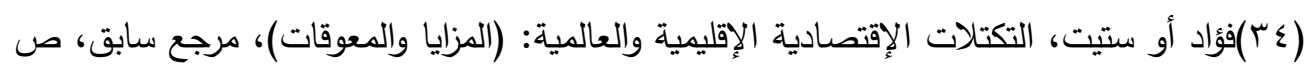


ومن الواضح أن أفريقيا تواجهه تحديات تثـل الأزمـة المالية العـالمية وأزمـة الطاقة والغذاء، وهو ما يُعد مؤشرًا واضحًا على ضرورة التتسيق بين التجمعات الاقتصـادية الاقليمية بغية التغلب على هذه التحديات، حيث أنه يستحيل على الدول فرادى التصدى لتلك التحديات، ويككن رصد أهم تلك التحديات فى النقاط التالية: 1-شكل الوصول إلى الطاقة وتأمينها أهم العقبات التى تواجه التكامل الاقتصادى بالقـارة ، فعلى الرغم من موارد الطاقة التى تزخر بها القارة، تظل امكانيات الوصول إلى الطاقة عند مستوى ادنى بكثير ما هو عليه

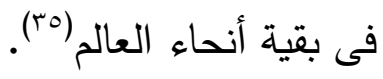
ץ-كما تصطدم عملية التكامل فى القارة بالعديد من النزاعات التى تسود بعض الدول الأعضاء والتى تعرقل جهود التكامل والتتمية، كما ينجم عنها تقليص لحجم الأنثطة الاقتصادية وتدمير البنية التحتية، علاوة على ما تفرضه من معوقات أمام تدفق التجارة والاستثمارات(؟T). (To مؤتمر الامم المتحدة للتجارة والتتمية (اونكتاد)، الثراكة الجديدة من أجل تتمية افريقيا: الاداء

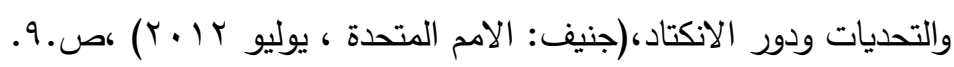
(דب)(بحم عاشور، مستقبل التكامل الاقليمى في أفريقيا، القاهرة، مركز دراسات المستقبل الإفريقي، 
ب-يُعد غيات آليات التــويل الذاتى لمنظمات التكامل الاقليمى أحد أهم التحديات التى تواجه عملية التكـامل بالقارة، كما لا تـوجد آليات تعويض الخاسرين بسبب عملية التكامل، وهو ما يثـكل عـائقًا أمام التنفيذ التام لمخططات التكامل، فالرسوم الجمركية وغيرها من الضرائب المفروضة على التجارة تمثل حصة كبيرة من ايرادات العديد من البلدان الأفريقية، فالخسارة المـتملة لهذه الايرادات اذا ما نفذت كل بروتوكولات عملية التكامل من شأنها أن تعـوق عملية التكامل، حتى ولو كانت الفوائد المحتملة للتكامل تفوق تكلفته، وفيما يتعلق بقضية التمويل فلقد حدد برنامج الحد الأدنى للتكامل ( MIP) عددًا من المـجالات والقـطاعات ذات الأولوية، ولكن التحدى تمثل فيه ايجاد مصادر تمويل رئيسية ومستقرة وطويلة الأجل، وفيما يخص هذه العقبة يسعى الاتحاد الافريقى إلى إنشاء مؤسسات مالية أفريقية مثل بنك الاستثمار الافريقى، وصندوق النقد الافريقى، والبنك المركزى الافريقى (rv).

مؤتمر الأمم المتحدة للتجارة والتتمية (اونكتاد)، الثراكة الجديدة من أجل تتمية افريقيا، 
ع - علاوة على ما تقدم فإن الانتشار الواسـع للعوائق والمـتاريس ونقاط

التفتيش على امتداد الطرق الأفريقية، يزيد من تكلفة النقل ويسهم أيضًا فى زيادة تأخير تسليم السلع، كما أن هذه العوائق تحد من حرية حركة السلع والأشخاص وعناصر الانتاج والاستثمارات، وعادة ما تثتقر الادارات الجمركية الأفريقية إلى الفعالية مما يسهم فى عرقلة حركة

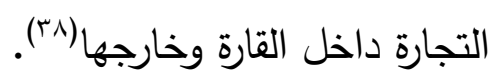

ه-وتوجد عراقيل إضافية تعترض التجارة تشمل نظم الـدفع والتأمين والتى تحتاج الى التطوير بشـل مستمر، أضف إلى ذلك أن نـظم التجارة الخارجية والتسهيلات الائتمانية للتصـدير والتأمين على الصادرات هى آليات غير متاحة فى معظم البلدان الأفريقية، ونتيجة لانعدام الموائمة بين اللوائح المالية والنقدية على المستوى الإقليمى والوطنى، فإن نظام التحويل

$$
\text { فيما بين العملات غير قائم(ج"). }
$$

(rᄉ) الأمم المتحدة، المجلس الاقتصادى والاجتماعى، اللجنة الاقتصادية لافريقيا، تقييم التقدم

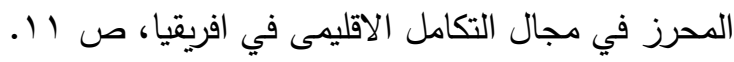
(ج) الأمم المتحدة، المجلس الاقتصادى والاجتماعى، اللجنة الاقتصادية لافريقيا ،مرجع سابق، 


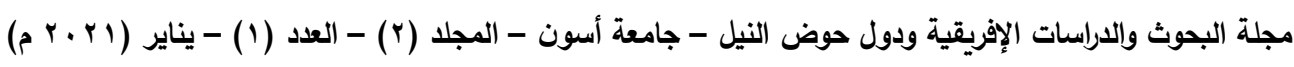

7-تعتبر شبكة الهياكل الأساسية والبنى التحتية فى أفريقيا ضعيفة للغاية

مقارنة بالمقاييس العالمية مما يعوق مستتيرة التكامل بالقارة، ومن

المستبعد أن تشهد التجارة الأفريقية البينية تحسنًا ملموسًا فى ظل الحالة

المتدنية التى تعانى منها البنية التحتية فى أفريقيا، عـلاوة على ذلك

تحتاج أفريقيا إلى تطوير البنى التحتية للطاقة مثل شبكات الكهباء

وخطوط أنابيب البترول والغاز ، والتى تسهم فى تسهيل تجارة الطاقة عبر

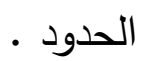

ومـن التحديات الرئيسية التى تواجـه تطوير البنى التحتية الأفريقية النقص

فى التمويل المناسب، فقد أشارت تقديرات البنك الدولى إلى أن حجم الاستثمار السـنوى لمتطلبات البنى التحتية فى أفريقيا تقدر بحوالى به بليون دولار أمريكى على مدى السنوات العشر للعقد القادم، لذا يلزم على البنك الدولى والاتحاد الاوروبى والبنك الافريقى للتنمية وغيرها من الوكالات المالية زيادة حجم تمويلها لتطوير البنية التحتية فى أفريقيا حيث تفتقر الحكومات الأفريقية إلى القدرات المالية اللازمة لتحقيق ذلك (๕). (

(40) UNCTAD,Trade Capacity Development for Africa ,Trade Negotiations and Africa, Series no.3,2006. 
V- هناك تباين واضـح بين دول التجمع أو بين التجمعات المختلفة، ومن أبرز

الأمـثلة على التفاوت فى الأوضاع الاقتصادية داخل التجمع الواحد

جنوب أفريقيا، حيث يتخطى مـتوسط دخل الفرد بها ـــ دولار

سـنويًا، فى حين أن مالاوى لا يتعدى متوسط دخل الفرد بها ـ. . ب دولار

سنويًا، ومن شأن هذه الفجوة الاقتصادية الهائلة بين مخـتلف الدول

الأفريقية أن تعطل مجرد إقامة حوار فيما بينها وفقًا لبرنامج مشترك مـا

يعنى إعاقة تكامل إقتصاداتها لتصبح إقتصادًا واحدًا، فإنشاء السوق

المشتركة التى تستلزم التوفيق بين السـياسات من أجل تحقيق حرية

الحركة لعناصر الانتاج من شأنه أن يعمل على تعزيز الوضع التنافسى

ودعم التنمية الصناعية ورفع مستوى الإنتاجية، إلا أن التباين الكبير الذى

تشـهده الـقارة فيما يتصل بمستويات التتمية الاقتصادية والصناعية يشكل

حاجزًا رئيسيًا أمسام عملية التكامل(1).

^-لم تضــع الجماعة الاقتصـادية الأفريقية إطارًا أو نظامًا يعالج إلتزامات

الدول الأفـريقية الأعضاء فى تجمع إقتصادى إقليمى تجاه تجمع آخر

(1) طارق عادل الثيخ، التجمعات الأفريقية، مقومات النجاح ومعوقات التكامل، مركز الاهرام

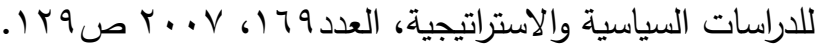


مجلة البحوث والدراسات الإفريقية ودول حوض النيل - جامعة أسون - المجلد (r) - العدد (1) - يناير ( ب · م م)

منضمة إليه، ومثال ذلك حالة أوغندا أو كينيا فكل منهما عضو فى جماعة الكوميسا وفى الوقت نفسه هما عضوان مؤسسان فى تجمع شـرق أفريقيا، وهو ما يخلق ازدواجية فى الخطوات اللازمة لتحقيق التكامل، ويـعد من عوامل الضعف الرئيسية فى عمل التجمعات الاقتصادية الأفريقية، كما يتعـارض هذا التداخل فى العضـوية مـع قواعد منظمة التجارة العالمية التى تتص على أن الدولة العضو بتجمع إقتصادى إقليمى ينبغى ألا تتضم الى أكثر من اتحـاد جمركى(זء). ودوافع التكتلات الإقتصادية في أفريقيا تختلف من فترة إلى أخرى، حسب الأحداث والمشاكل المعيشة، ويمكن تقسيم دوافع إنشاء التكتلات الإقتصادية الإقليمية في أفريقيا إلى دوافع سياسية وأخرى إقتصادية على النحو التالي:

(أ)الأسلوب الاستعماري الجديد (Neocolonialism)، والذي خطط

لاستنزاف خيرات أفريقيا وتعميق ثقافة التبعية الإقتصادية ونتج عنه: 1-حالة التخلف الذي تعيشه أفريقيا.

(ץ) الاونكتاد، التكامل الاقليمى والاستثمار الاجنبى البباشر في الاقتصادات النامية والانتقالية، صזו. 10r 
Y-انخفاض شروط تبادل المواد الأولية بالنسبة للمواد المصنعة.

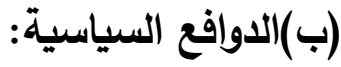

قد كانت الرغبة في تحرير القارة من الاستعمار هي الهدف الرئيسي لمحاولات الوحدة الأفريقية الإقتصادية في وقت من الأوقات، سواء كان استعمارًا مباشرًا أو تفرقة عنصرية، ولكن سرعان ما تلاشى هذا الدافع بعد أن نالت دول أفريقيا استقلالها. الرغبة في إبعـاد القارة من التطاحن بين المعسكرين الثرقي والغربي باتخاذ سياسة عدم الإنحياز، ويبدو هذا جليًا في إنضمام معظم دول إفريقيا المستقلة آنذاك لمجموعة دول عدم الإنحياز وتقليل المشاكل السياسية المتمثلة في النزاعات الـحدودية والعرقية، وكثرة الحروب بين الشعوب الأفريقية.

والواضح أن الدوافع الأساسية للتكتلات الإقتصـادية الأفريقية هي دوافع اقتصادية وحدودية حيث تعتبر هذه التكتلات النواة الأساسية للوحدة الإقتصادية 
مجلة البحوث والدراسات الإفريقية ودول حوض النيل - جامعة أسون - المجلد (r) - العدد (1) - يناير ( ب · م م)

الأفريقية وأن جميع محاولات التكامل الإقتصادي قد تمت في إطار منظمة الوحدة الأفريقية والجماعة الإقتصادية الأفريقية(ז؟).

\section{الخاتمة}

أن التطـورات التي تجري في العـالم المتقدم السياسـية منها والاقتصـادية من

شأنها أن تشكل محفزًا للدول الإفريقية للقيام محفزًا بإنشاء تكتلات اقتصـادية إقليميـة تخدم مصـالحها وتمكنها من مواجـهة عالم اليوم الذي هو عالم التكـتلات الاقتصـادية الكبـرى ، حيـث ان التكامل الاقتصـادي أصبح اليوم وسيلة متفقا عليهـا مـن قبل المهتمين بموضوع التتميـة ، باعتبارها الوسيلة الأكثر ضـمانًا للوصول إلى مســويات معتبرة مـن التتميـة الاقتصـادية ، وزيـادة رفاهيـة الثـعوب مهما اختلفت الطرق والأساليب والمفـاهيم المستخدمة والمعبرة عن هذه الوسيلة

ومن اجل بـناء ذلك فإن التكتلات الاقتصـادية بين الدول الإفريقية تستطيع

ان تواكب روح العصر فأن الامـر يتطلب تتمية الموارد البشرية وتكوين المهارات و التقليل من درجـة الاعتمـاد على المسـاعدات الخارجيـة و العمـل على نبذ الخلافات الناشئة بين الدول النامية، و اتخاذ خطــوات جـادة نحـو بنــاء (r) يوسف خميس أبو رفاس، التكتلات الإقتصادية في شرق أفريقيا وجنوبها، مرجع سابق، ص 
المؤسسـات الديمقراطية ، باعتبارها الطريق السليم للوصول الى الاستقرار السياسي وصيانة المكاسب.

$$
\text { وتمثلت أهم النتائج فى : }
$$

من خلال البحث تم التوصل إلى عدة نتائج منها:

1-قامت التكتلات الاقتصادية فى ظل التدهور الاقتصادى للدول الأفريقية

على أساس تتمية دول أفريقيا والتباين ما بين الدول ثقافيا وايدلوجيا واختلاف العقائد ما بين الفكر الراسمالى والغربى والثيوعى الثرقى

ץ-تعتبر التكتلات الاقتصادية خطوة مهمة وضرورية نحو تحقيق التكامل

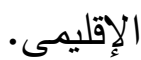

ب-إن التكامل الاقتصادى أصبح اليوم وسيلة متفقا عليها من قبل الباحثين باعتباره الوسيلة الأكثر ضمانا للوصول إلى مستويات معتبرة من التنمية الاقتصادية وزيادة رفاهية الشعوب مهما اختلفت الطرق والأساليب.

ع-تمكنت الدول الإفريقيتمن إنشاء تكتلات اقتصاديتلها برامج وسياسات ومؤسسات تهدف إلى تحقيق أهداف الجماعة الاقتصادية الإفريقية عبر مراحلها ولكنها تسير ببطء 


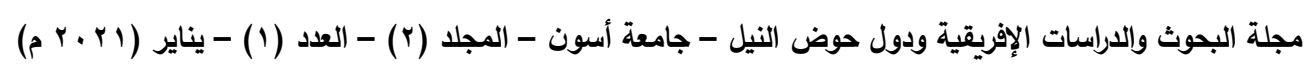

○-أن العديد من الدول الإفريقية تمتع بالعديد من موارد طبيعية متتوعة والموقع الجغرافى الاستراتيجى يمثل فرصة لنجاح تجارب تكملية بين العديد من الدول منها.

7-هناك دور كبير تقوم به التكتلات الاقتصادية فى تحقيق السلم لأمن الإفريقين وتعتبر الايكواس هى الرائدة فى هذا المجال حيث أنها انشات آلية بالايكموج تقوم بإحلال السلم بل وفرضـه.

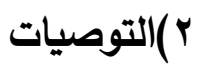

ا-تجاوز السلبيات والمعوقات التي تواجه التكتلات الإقليمية حتى يتسنى لها

القيام بأدوارها.

ץ- توسيع تجربة التكتلات الإقتصادية لتشمل كل أقاليم القارة وصولا إلى التكامل الإفريقي لكل القارة حتى يتم التوصل إلا الولايات الإفريقية المتحدة.

r- تعميم تجربة الايكموج في حفظ وفرض السلام على بقية التكتلات الإقليمية الموجودة حتى يتحقق السلم والأمن الدوليين 
ع - بناء علاقات سياسية وخارجية تقوم على أسس حسن الجوار بين الدول

$$
\text { وسياسة عدم التدخل في الثأن الداخلي تحقيق الأهداف التكتلات الإقليمية. }
$$

\section{المراجع}

\section{أولا- المراجع باللغة العربية}

() الأمم المتحدة، المجلس الاقتصادى والاجتماعى، اللجنة الاقتصادية لافريقيا،

$$
\text { تقييم التقدم المحرز في مجال التكامل الاقليمى في افريقيا }
$$

r) الاونكتاد، التكامل الاقليمى والاستثمار الاجنبى المباشر في الاقتصادات

$$
\text { النامية والانتقالية. }
$$

r) بلوافى ححد، المنظمات الإقليمية في إفريقيا، مجلة جامعة أحمد دراية أدرار ،

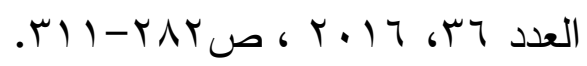

ع) بيلا بلاسا، نظرية التكامل الإقتصادي، ترجمة رشيد البراوي، دار النهضة

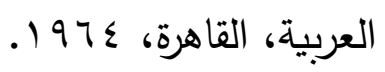


0) جمال الدين أبو بكر، التكامل الاقتصادي العربي والمشكلات التي تواجهه،

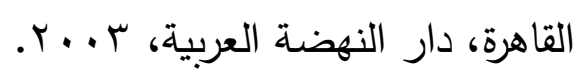

7) حسن مصطفى سلامة، الجماعة الاقتصادية الإفريقية ، قراءة قانونية

$$
\text { "السياسة الدولية ، دار الفؤاد للنشر، ب999 ا. }
$$

(V حمدي عبد الرحمن، أفريقيا والعولمة، القاهرة، برنامج الدراسات المصرية

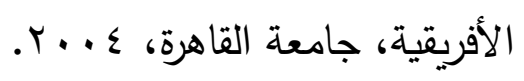

^) خليفة مصمونى، التكامل بين المنظمات الاقليمية الفرعية الافريقية ودوره في تحقيق الوحدة الافريقية، كلية الحقوق والعلوم السياسية، جامعة تلمسان،

$$
. r \cdot 10
$$

9) راوية توفيق، المشروطية السياسية والتحول الايموقراطي في أفريقيا، سلسلة دراسات إفريقية، القاهرة، برنامج الدراسات المصرية الإفريقية ، جامعة القاهرة،

$$
. r \ldots r
$$

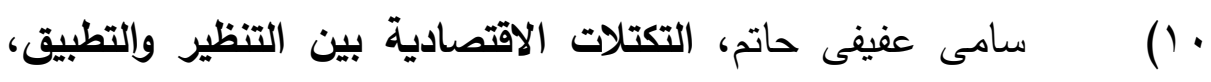

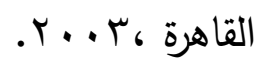

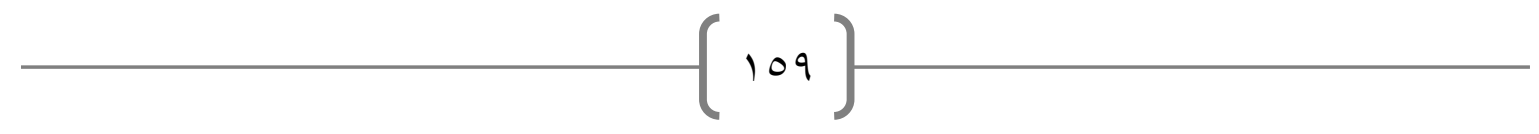


طارق عادل الثيخ، التجمعات الأفريقية، مقومات النجاح ومعوقات

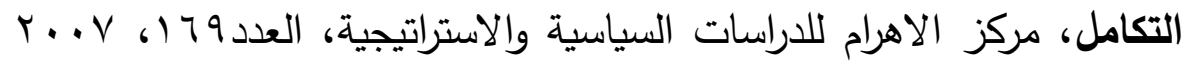

الطاهر حمح أحمد الفادنى ، الأثار السياسية للتكتلات الاقتصادية فى

إفريقيا، رسالة ماجستر ، جامعة النيلين، كلية الدراسات العليا، الخرطوم،

$$
. r \cdot 11
$$

عائشة خلوفى، انعكاسات الاتجاه المتزايد نحو التكتل الاقتصادى

الإقليمى على حركة التبادل التجارى الدولى : دراسة حالة الاتحاد الاوربى ،

مجلة الحقوق والعلوم الإنسانية ، جامعة زيان عاشور بالجلفة ، المجلد 11 ،

$$
. r \cdot 11
$$

عبد السلام صالح عرفة، المنظمات الإقليمية والدولية، الدار

الجماهيرية للنشر والإعلان ،دار الكتاب للنشر، طرابلس، 999 (.

عبد المطلب عبد الحميد، النظام الاقتصادي العالمي الجديد وآفاقه

المستقبلية بعد أحداث 1 سبتمبر .القاهرة، مجموعة النيل العربية، . . ؟. 
عبد الوهاب الآمين، بشير طاهر فريد، التجارة العربية الافريقية

ودورها في دعم التنمية في الآقطار الإفريقية جنوب الصحراء، المصرف

العربي للتنمية الاقتصادية في إفريقيا، مركز المعرفة للاستثارات والخدمات

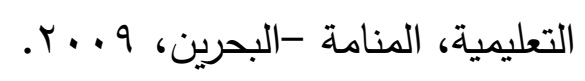

عبد الرحيم يونس، دور التجمعات الإقليمية فى دعن التكامل

الاقتصادى الأفريقى، دراسة على التجمعات الرئيسية فى القارة ، معهد البحوث

والدراسات العربية بالمنظمة العربية والثقافة والعلوم ، القاهرة ، م. . ب .

عبد القادر السيد متولي، الإقتصاد الدولي: النظرية والسياسيات، دار

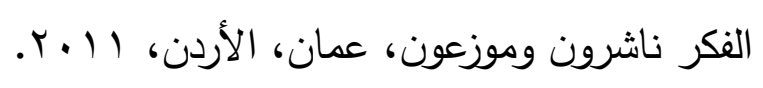

عبيد إميجن سالم، المجموعة الاقتصادية لدول غرب افريقيا "

الايكواس ..مقومات النجاح وقيود التكامل .تاريخ الاستردادبr أكتوبر

$$
\text { .r. . . }
$$

على عبد الله المناعى، التكتلات الاقتصادية ودورها فى تطوير البنية،

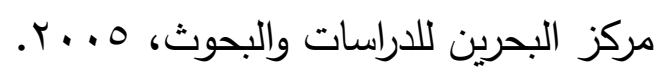

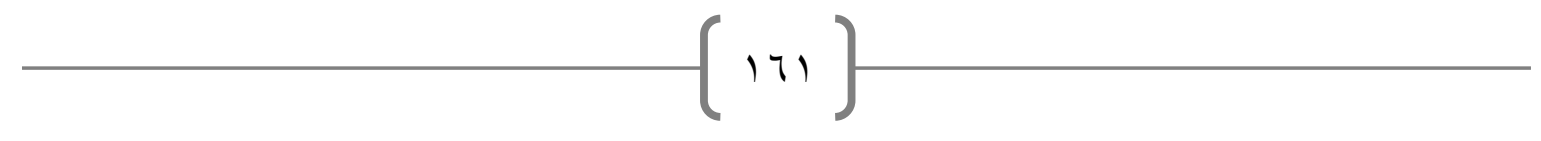


عماد الليثى ، بعد نصف قرن، التكامل الاقتصادي العربي،

$$
\text { القاهرة،دار النهضة العربية r . . r. }
$$

عمر الجيلي الثيخ الأمين، المصرف العربي للتمية الإقتصادية في

أفريقيا (التعاون العربي الأفريقي من أجل منافع إقتصادية متبادلة: المحفزات

$$
\text { والتحديات في ظل العولمة ، } 9 \text {. . ب. }
$$

فرج عبد الفاح فرج، الاقتصاد الإفريقى من التكامل الإقليمى إلى

$$
\text { العولمة ، دار النهضة العربية، القاهرة، ا ... ا. }
$$

فرج عبد الفتاح فرج، إمكانيات التعجيل بتنفيذ الجماعة الاقتصادية

الأفريقية فى ظل الاتحاد الأفريقى ، بحث مقدم لمؤتمر الاتحاد الافريقى،

$$
. r .11
$$

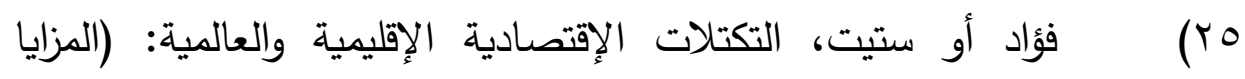
والمعوقات)، المجلة العلمية للبحوث والدراسات التجارية، جامعة حلوان، كلية

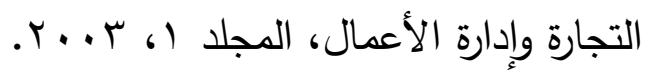


محمد عاشور مهدى، مستقبل التكامل الإقليمى فى افريقيا : قراءة فى

ضوء الدوافع والواقع والتحديات قراءات إفريقية ، المنتدى الإسلامى، العد 7

$$
. r \cdot 1 \cdot 6
$$

محمد عاشور، الحدود السياسية وواقع الدولة في أفريقيا، القاهرة،

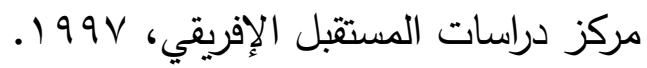

محم لبيب شقير ، الوحدة الاقتصادية العربية تجاربها وتوقعاتها، ج)

$$
\text { مركز دراسات الوحدة العربية، بيروت، ب^9 اص •9. }
$$

محمد محمود الإمام، تجارب التكامل العالمية ومغزاها للتكامل العزبي،

$$
\text { القاهرة، مركز دراسات الوحدة العربية؛ . .. . . }
$$

محمد محمود الإمام، تجارب التكامل العالمية ومغزاها للتكامل العزبي،

$$
\text { القاهرة، مركز دراسات الوحدة العربية،، ع . . . . }
$$

مفتاح سويسى الفرجانى، الاتحاد الإفريقى فى ظل التكتلات الاقليمية

والدولية، بحث مقدم للندوة التى نظمتها كلية القانون بجامعة طرابلس ـ. . . 
مؤتمر الامم المتحدة للتجارة والتتمية (اونكتاد)، الشراكة الجديدة من

أجل تتمية افريقيا: الاداء والتحديات ودور الانكتاد،(جنيف: الامم المتحدة ،

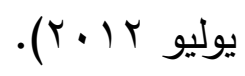

مؤتمر الأمم المتحدة للتجارة والتتمية (اونكتاد)، الثراكة الجديدة من

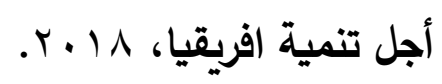

هويدا عبد العظيم، التكتلات الاقتصادية الافريقية: التبادل التجارى

ضرورة تموية، مجلة مركز الخليج للأبحاث، الامارات، المجلد^^، العدد

$$
. r \cdot 17 \cdot 6.9
$$

\section{ثانيًا- - المراجع باللغة الإنجليزية}

1) Mohamed Haddar, "Economic Integration In Africa From Speech To Reality" in Development And SocioEconomic Progress.( Vol.4, No.53, 1992), pp 5-6

2) UNCTAD,Trade Capacity Development for Africa ,Trade Negotiations and Africa, Series no.3,2006 